\title{
Blood pressure control and its determinants among diabetes mellitus co- morbid hypertensive patients at Jimma University medical center, South West Ethiopia
}

Sintayehu Muleta ${ }^{1}$, Tsegaye Melaku ${ }^{1 *}$ (D) Legese Chelkeba ${ }^{1}$ and Desta Assefa ${ }^{2}$

\begin{abstract}
Background: Hypertension is the major contributor to cardiovascular diseases related morbidity and mortality. Blood pressure is not well controlled in the majority of patients with both diabetes and hypertension. The main objective of this study was to assess blood pressure control and its determinants among diabetes mellitus co- morbid hypertensive ambulatory patients.

Methods: Hospital based cross sectional study was conducted among diabetes mellitus co-morbid hypertensive ambulatory adult patients based on the inclusion criteria. Patient specific data was collected using structured data collection tool. Data was analyzed using statistical software package, SPSS version 20.0. To identify the independent predictors of blood pressure control, multiple stepwise backward logistic regression analysis was done. Statistical significance was considered at $p$-value $<0.05$. Patient's written informed consent was obtained after explaining the purpose of the study. Patients were informed about confidentiality of the information obtained.
\end{abstract}

Results: From a total of 131 study participants $51.14 \%$ were males with the mean (SD) age of the $50.69 \pm 13.71$. The mean duration of time since the diagnosis of hypertension was $7.44 \pm 5.11$ years. The mean (SD) SBP was $149.79 \pm 16.32 \mathrm{mmHg}$, while the mean (SD) DBP was $89.77 \pm 9.34 \mathrm{mmHg}$. More than one fourth (25.20\%) of study participants had a controlled SBP, while about $27.48 \%$ had a controlled DBP. The overall control of BP was achieved in about 57 (43.51\%) of the study participants. Older age ( $\geq 50$ years) ( $\mathrm{AOR}=2.06 ; 95 \% \mathrm{Cl}: 2.65-7.79 ; P=0.002)$, female gender ( $\mathrm{AOR}=1.42 ; 95 \% \mathrm{Cl}: 1.19-2.14$; $P=0.042$ ), duration of hypertension ( $A O R=2.88,95 \% \mathrm{Cl}: 1.27,8.31, P=0.02)$, non-adherence (AOR 2.05; 95\% Cl: 2.61-9.33; $P=0.01)$ and uncontrolled blood sugar( $(\mathrm{AOR}=1.65 ; 95 \% \mathrm{Cl}: 2.14-3.32 ; P=0.04)$ are independent predictors for uncontrolled blood pressure.

Conclusions: Blood pressure control to target goal was suboptimal in the study area. Diabetic patients who were older, female, live longer duration with hypertension, non-adherent to their medications and poor glycemic control were more likely to have uncontrolled BP. Therefore, more effort should be dedicated to control the blood pressure in diabetics.

Keywords: Hypertension, Diabetes mellitus, Blood pressure control, Uncontrolled hypertension

\footnotetext{
* Correspondence: tsegayemlk@yahoo.com; tsegaye.melaku@ju.edu.et 'Department of Clinical Pharmacy, School of Pharmacy, Institute of Health, Jimma University, P.O.Box:378, Jimma, Oromia, Ethiopia

Full list of author information is available at the end of the article
} 


\section{Background}

Hypertension is the major contributor to the global burden of disease and to global mortality [1]. It is defined as persistently elevated arterial blood pressure (BP), systolic BP $(\mathrm{SBP}) \geq 140 \mathrm{mmHg}$ and/or diastolic BP $(\mathrm{DBP}) \geq 90 \mathrm{mmHg}[2,3]$. These numbers apply to all adults older than 18 years and indicate the level of BP at which the institution of therapy reduces hypertension related morbidity and mortality [3], although for patients aged 60 years or older a SBP up to $150 \mathrm{mmHg}$ and a DBP of less than $90 \mathrm{mmHg}$ is now regarded as acceptable [4]. The global prevalence of raised BP in adults aged 18 years and over was around 22\% in 2014 [5] and the proportion is estimated to rise to over $29 \%$ by 2025 [6]. The prevalence of hypertension was highest in Africa, at $30 \%$ for all adults combined in 2014 [7]. Hypertension has shown a rapid increase in prevalence affecting significant numbers of individuals in SubSaharan Africa [8]. The prevalence in Sub- Saharan Africa is in the range of $25.4 \%-41.1 \%$ in men and $27.2 \%-38.7 \%$ in women [9]. The reported prevalence of hypertension in different regions of Ethiopia varied widely $[10,11]$. The prevalence in the country is estimated to be between 20\% and 30\% [12]. Hypertension also clusters with other cardio-metabolic conditions, namely diabetes, dyslipidemia, insulin resistance, glucose intolerance and obesity [10], which together increase cardiovascular disease risk [10-12].

There are several co-existing factors in diabetic patient which contribute for and accelerate the progression of the atherosclerotic vascular complications. Hypertension, which is the most prevalent and independent cardiovascular risk factor in the general population, is extremely common problem in diabetics [4]. Diabetes approximately doubles risk of cardiovascular disease and concomitant hypertension nearly doubles that risk again. In addition to diabetes related renal dysfunction, hyperinsulinemia, extracellular fluid volume expansion, and increased arterial stiffness have been proposed as contributing factors for the development of hypertension in diabetics [3]. Based on the evidence provided by clinical trials, current guidelines recommend that patients who have been diagnosed with cardiovascular disease and its equivalents should reduce their blood pressure to $<140 / 90 \mathrm{mmHg}$ (so does in the case diabetics) [7]. Further, it is recommended that low density lipoprotein cholesterol (LDL-C) levels should be reduced to $<100 \mathrm{mg} / \mathrm{dL}(2.5 \mathrm{mmol} / \mathrm{L})$. Unfortunately, these therapeutic goals are not always attained [4, 7].

Drug treatments and life style interventions can be used for the management of hypertension [2]. Several lifestyle interventions have been shown to reduce BP. Apart from contributing to the treatment of hypertension; these strategies are beneficial in managing most of the other cardiovascular disease (CVD) risk factors [3]. Lifestyle modifications should be encouraged for all patients, regardless of stage of hypertension and includes smoking cessation, weight management, and reduction of dietary sodium intake, physical activity and moderation of alcohol consumption [13]. In general, lifestyle changes should be regarded as a complement to drug therapy rather than an alternative [7]. Drug treatment of hypertension depends on the degree of BP elevation and presence of compelling indications [2]. Most patients with stage 1 hypertension should be initially treated with a first-line antihypertensive drug, or a combination of two agents. Combination drug therapy is recommended for patients with stage 2 hypertension using preferably two first-line antihypertensive drugs [4]. According to the eighth report of the Joint National Committee (JNC 8 ); in the general non-black population, including those with diabetes, initial antihypertensive treatment should include a thiazide-type diuretic, calcium channel blockers (CCBs), angiotensin-converting enzyme inhibitors (ACEIs), or angiotensin receptor blockers (ARBs); whereas in the general black population, including those with diabetes, initial antihypertensive treatment should include a thiazide-type diuretic or CCB. For patients with chronic kidney disease (CKD), initial (or add-on) antihypertensive treatment should include an ACEI or ARB to improve kidney outcomes [4]. All the first line drugs classes have comparable outcome benefits [14].

The success of blood pressure management in hypertensive individuals is determined by the integrated use of optimal dose and regimen of anti-hypertensive medications together with an intervention targeted on life style modification. These have to be guided by the knowledge of the specific characteristics of patients group. Since the success of treating hypertension has been limited, and despite well-established approaches to diagnosis and treatment, in many communities fewer than half of all hypertensive patients have adequately controlled BP. This result will be expected to be lower among diabetic co-morbid patients. To date there is no single study done in Ethiopia to assess blood pressure control among hypertensive diabetics. Thus, this study is designed to highlight the status of uncontrolled hypertension in patients with type 2 diabetes and determine the associated factors, which may affect the blood pressure management and find the bottle neck and pave the way for interventions.

\section{Methods}

\section{Study design and setting}

A hospital based cross-sectional study design was conducted in March, 2017 at ambulatory clinic of Jimma University Medical Center (JUMC) among diabetes comorbid hypertensive patients who fulfill the inclusion 
criteria. JUMC is the only teaching and referral hospital in the southwestern part of Ethiopia with bed capacity of 600. Geographically, it is located in Jimma town $352 \mathrm{~km}$ Southwest of Addis Ababa, the capital. It provides services for approximately 9000 inpatient and 80,000 outpatient clients per year with a catchment population of about 15 million people. All ambulatory hypertensive diabetic patients aged 18 years and older who were on antihypertensive treatment for at least 6 months before the study period and were on follow-up were included in the study.

\section{Sample size and sampling procedure}

The sample size was determined by using the single population proportion formula, assuming a 95\% confidence interval $(\mathrm{CI})$, a prevalence of $50 \%$ for blood pressure control, a 5\% margin of error, and a 10\% nonresponse rate. The final sample size was 131 diabetic hypertensive patients. Random sampling technique was used to select 131 study participants after obtaining patient list from Chronic Illness Clinic Registration Book, which had lists of 557 hypertensive patients, of which 173 were with diabetes comorbidity.

\section{Data collection, procedure and quality control}

A structured data collection questionnaire was developed by researchers from relevant literatures. Patient chart review and self-report was used to determine the various variables. Two trained data collectors interviewed the study participants and review patient charts and medical records for the respective information after all data collection tools are pre-tested. Before entry to SPSS for analysis, data was cleared, categorized, compiled and coded and also checked for completeness, accuracy. Any erroneous, ambiguous and incomplete data was excluded.

\section{Data processing and analysis}

Data was entered into computer using EpiData version 3.1 and exported to the Statistical package for Social Science (SPSS) version 22.0 for analysis. Differences between mean values was evaluated using Student's t test while proportions was compared using the Pearson's Chi-square test. Multivariable logistic regression analyses were used to assess the crude and adjusted effect of seemingly significant predictors of the target outcome.

Categorical and continuous data was expressed as percentages and mean \pm standard deviation respectively. Descriptive statistics was applied for the analysis of patient characteristics, including means, standard deviations (SD), medians, and percentiles and categorical variables was analyzed by using the chi-square test. A $p$-value of $<0.05$ was considered to be statistically significant.

\section{Ethical consideration}

Ethical clearance \& approval was obtained from institution review board (IRB) of Jimma University. The data that were collected from JUMC ambulatory clinic was preceded by a formal request letter from Jimma University. Written informed consent was taken from each study participant after clear orientation of the study objective. The raw data were not made available to any one and not used as the determinant of the participant. All steps in data collection and compilation were conducted and supervised by the researchers. Strict confidentiality was assured through anonymous recording and coding of questionnaires and placed in safe place. The patient got full right not to participate and as well as leave the study at any time during the study time.

\section{Operational definitions}

Co-morbidity: Diseases or disorders that exist together with an index disease or co-occurrence of two or more diseases or disorders in an individual.

- Controlled BP: BP < 140/90 mmHg in hypertensive diabetic patients of all ages [4].

- Uncontrolled BP: BP $\geq 140 / 90 \mathrm{mmHg}$ in hypertensive diabetic patients of all ages [4].

adherent: a patient with a MMMAS score of $\geq 6$ [15] .

- Non adherent: a patient with a MMMAS scores of $<6$ [15].

Physically active: an individual who perform physical exercise for at least $30 \mathrm{~min}$ per day for at least 5 day per week.

- Physically inactive: an individual who perform physical exercise for less than $30 \mathrm{~min}$ per day for less than 5 day per week [16].

- Controlled blood sugar: Fasting blood sugar less than $130 \mathrm{mg} / \mathrm{dL}$ [17].

- Uncontrolled blood sugar: Fasting blood sugar less than $130 \mathrm{mg} / \mathrm{dL}$ [17].

\section{Results}

Socio-demographic and behavioral characteristics

Overall, 131 participants were included in this study. Majority of study participants were males 67 (51.14\%). The mean weight of the respondents was $67.9 \pm 13.01$. The mean age of the respondents was $50.69 \pm 13.71$ and majority of them 67 (51.14\%) were age of $\geq 50$ years, 109 $(83.20 \%)$ were married. Among the participants, 21(16.03\%) were current smokers and 23 participants reported their current use of alcohol and 35 (26.72\%) had no formal education and $44(33.60 \%)$ were unemployed. About three forth of the study participants were found to be adherent to their medication according to a self-reported measure of adherence using the eight item MMMAS (Table 1). 
Table 1 Baseline socio-demographic characteristics of study participants at JUMC, 2017

\begin{tabular}{|c|c|c|c|}
\hline Variables & & Frequency & Percentage \\
\hline \multirow[t]{3}{*}{ Age(years) } & $18-35$ & 18 & 13.74 \\
\hline & $36-50$ & 46 & 35.12 \\
\hline & $\geq 50$ & 67 & 51.14 \\
\hline $\begin{array}{l}\text { Weight }(\mathrm{kg})(\text { Mean } \pm \\
\text { SD) }\end{array}$ & $67.9 \pm 13.01$ & & \\
\hline \multirow[t]{2}{*}{ Gender } & Male & 67 & 51.14 \\
\hline & Female & 64 & 48.86 \\
\hline \multirow[t]{4}{*}{ Marital Status } & Single & 11 & 8.40 \\
\hline & Married & 109 & 83.20 \\
\hline & Divorced & 4 & 3.05 \\
\hline & Widowed & 7 & 5.35 \\
\hline \multirow[t]{4}{*}{ Educational status } & No formal education & 35 & 26.72 \\
\hline & Primary school & 33 & 25.19 \\
\hline & Secondary school & 27 & 20.61 \\
\hline & College and above & 36 & 27.48 \\
\hline \multirow[t]{5}{*}{ Monthly Income (ETB) } & No regular income & 41 & 31.30 \\
\hline & $<1000$ & 21 & 16.03 \\
\hline & $1000-2000$ & 19 & 14.50 \\
\hline & 2000-3000 & 18 & 13.74 \\
\hline & $\geq 3000$ & 32 & 24.43 \\
\hline \multirow[t]{2}{*}{ Residence } & Rural & 40 & 30.53 \\
\hline & Urban & 91 & 69.47 \\
\hline \multirow[t]{4}{*}{ Job/occupation } & Gov't employee & 30 & 22.90 \\
\hline & Non-Gov't employee & 19 & 14.50 \\
\hline & Self employed & 38 & 29.00 \\
\hline & Unemployed & 44 & 33.60 \\
\hline \multirow[t]{4}{*}{ Living status } & $\begin{array}{l}\text { Living with immediate } \\
\text { family }\end{array}$ & 113 & 86.25 \\
\hline & $\begin{array}{l}\text { Living with Extended } \\
\text { family }\end{array}$ & 10 & 7.63 \\
\hline & Living alone & 5 & 3.82 \\
\hline & Other* & 3 & 2.30 \\
\hline Smoker & & 21 & 16.03 \\
\hline Alcoholic & & 23 & 17.56 \\
\hline Chat chewer & & 36 & 27.48 \\
\hline \multirow[t]{2}{*}{ Adherence level } & Adherent & 97 & 74.05 \\
\hline & Non-adherent & 34 & 25.95 \\
\hline
\end{tabular}

*Living in prison

\section{Clinical characteristics of participants}

The clinical characteristics of patients showed that 23 (17.56\%) of participants had a family history of hypertension and 18 (13.74\%) had family history of diabetes. About $46.56 \%$ and $48.10 \%$ of patients were living with hypertension and diabetes for more than five [5] years, respectively. More than half the patients had a monthly follow up at
JUMC ambulatory clinic. From 43 (32.82\%) patients with co-morbid conditions, 21 (16.03\%) had eye problem. The mean duration of time since the diagnosis of hypertension was $7.44 \pm 5.11$ with a range of $0.7-22$ year. With regard to physical exercise; 56 (42.74\%) of participants reported to perform physical exercise from whom $35(62.50 \%)$ were physically active. Among the study participants, 117 $(89.31 \%)$ reduce salt in their food (Table 2).

\section{Antihypertensive and hypoglycemic medications}

The overall utilization of antihypertensive drugs showed that, majority of patients were on dual antihypertensive (67.94\%). About one thirds of the patients were on combination of enalapril and amlodipine followed by hydrochlorothiazide and enalapril (17.55\%) combinations. About $8.40 \%$ of patients were taking triple antihypertensive

Table 2 Baseline clinical characteristics of study participants at JUMC, 2017

\begin{tabular}{|c|c|c|c|}
\hline Variables & & Frequency & Percentage \\
\hline \multirow[t]{2}{*}{ Family history of hypertension } & Yes & 23 & 17.56 \\
\hline & No & 108 & 82.44 \\
\hline \multirow[t]{2}{*}{ Family history of Diabetes } & Yes & 18 & 13.74 \\
\hline & No & 113 & 86.26 \\
\hline \multirow{3}{*}{$\begin{array}{l}\text { Time since hypertension } \\
\text { diagnosis(years) }\end{array}$} & $\leq 1$ & 25 & 19.08 \\
\hline & $2-5$ & 45 & 34.35 \\
\hline & $\geq 5$ & 61 & 46.56 \\
\hline \multirow{3}{*}{$\begin{array}{l}\text { Time since diabetes } \\
\text { diagnosis(years) }\end{array}$} & $\leq 1$ & 21 & 16.03 \\
\hline & $2-5$ & 47 & 35.87 \\
\hline & $\geq 5$ & 63 & 48.10 \\
\hline \multirow[t]{3}{*}{ Frequency of followup(refill) } & Monthly & 71 & 54.20 \\
\hline & $\begin{array}{l}\text { Every two } \\
\text { months }\end{array}$ & 41 & 31.30 \\
\hline & $\begin{array}{l}\text { Every three } \\
\text { months }\end{array}$ & 19 & 14.50 \\
\hline \multirow[t]{2}{*}{ Do physical activities } & Yes & 56 & 42.74 \\
\hline & No & 75 & 57.26 \\
\hline \multirow[t]{2}{*}{ Physical active } & Yes & 35 & 62.50 \\
\hline & No & 21 & 37.50 \\
\hline \multirow[t]{2}{*}{ Reduce salt intake } & Yes & 117 & 89.31 \\
\hline & No & 14 & 10.69 \\
\hline \multirow[t]{2}{*}{ Blood glucose } & Controlled & 86 & 65.65 \\
\hline & Uncontrolled & 45 & 34.35 \\
\hline \multirow[t]{6}{*}{ Comorbidity } & Heart failure & 5 & 3.82 \\
\hline & HIV/AIDS & 2 & 1.53 \\
\hline & CKD & 5 & 3.82 \\
\hline & Asthma & 3 & 2.30 \\
\hline & Retinopathy & 21 & 16.03 \\
\hline & Other $^{a}$ & 7 & 5.34 \\
\hline
\end{tabular}

${ }^{\mathrm{a} E p i l e p s y, ~ p e r i p h e r a l ~ n e u r o p a t h y ~}$ 
medications. About two thirds of the patients were taking insulin (Table 3).

\section{Blood pressure control among hypertensive diabetics} The mean SBP was $149.79 \pm 16.32$, while the mean DBP was $89.7 \pm 9.34$. More than one fourth of study participants had a controlled SBP; while about $27.48 \%$ had a controlled DBP. The overall control of BP was achieved in about 57 (43.51\%) of the study participants (Fig. 1).

\section{Determinants of uncontrolled blood pressure in diabetic patients}

The association of independent variables with the dependent variable was investigated using both univariate and multivariate logistic regression techniques. In univariate logistic regression analysis; age, gender, marital status, education level, alcohol intake, smoking, duration with hypertension (HTN), frequency of follow up, blood sugar(glycemic control), comorbidities and medication adherence showed association with BP control and hence, were used in multivariate analysis. The result of the multivariate analysis showed age to be significantly associated with uncontrolled BP in that

Table 3 Antihypertensive \& hypoglycemic Agents among study participants at JUMC, 2017

\begin{tabular}{|c|c|c|}
\hline Medications & Frequency & Percentage \\
\hline \multicolumn{3}{|l|}{ 1. Antihypertensive agents } \\
\hline Monotherapy & 31 & 23.66 \\
\hline Enalapril & 14 & 10.68 \\
\hline Amlodipine & 9 & 6.87 \\
\hline Nifedipine & 4 & 3.05 \\
\hline Hydrochlorothiazide & 3 & 2.29 \\
\hline Atenolol & 1 & 0.76 \\
\hline Dual therapy & 89 & 67.94 \\
\hline Hydrochlorothiazide + Enalapril & 23 & 17.55 \\
\hline Hydrochlorothiazide + Atenolol & 7 & 5.34 \\
\hline Enalapril + Amlodipine & 43 & 32.82 \\
\hline Atenolol + Amlodipine & 2 & 1.53 \\
\hline Enalapril + Atenolol & 12 & 9.16 \\
\hline Losartan +Amlodipine & 2 & 1.53 \\
\hline Triple Therapy & 11 & 8.40 \\
\hline $\begin{array}{l}\text { Hydrochlorothiazide + Enalapril + } \\
\text { Amlodipine }\end{array}$ & 5 & 3.82 \\
\hline Furosemide + Enalapril +Amlodipine & 2 & 1.53 \\
\hline Metoprolol + Enalapril + Furosemide & 4 & 3.05 \\
\hline \multicolumn{3}{|l|}{ 2. Antidiabetic agents } \\
\hline Insulin & 59 & 45.04 \\
\hline Oral hypoglycemic & 45 & 34.35 \\
\hline Insulin + Oral hypoglycemic & 27 & 20.61 \\
\hline
\end{tabular}

patients aged $\geq 50$ years were two times $(\mathrm{AOR}=2.06$; 95\% CI: $2.65-7.79 ; \quad P=0.002$ ) more likely to have uncontrolled BP than those $<50$ years. Patients with tertiary level education were $74 \%(\mathrm{AOR}=0.26$; $95 \% \mathrm{CI}$ : $0.13-0.54 ; P=0.03$ ) less likely to have uncontrolled BP than those with no formal education. Gender was also found to have association with uncontrolled BP, in that female patients have 1.42 times more likely (AOR $=1.42$; 95\% CI: $1.19-2.14 ; P=0.042$ ). Duration of hypertension since diagnosis was also associated with uncontrolled BP, in that patients with a diagnosis longer than 5 years were almost three times $(\mathrm{AOR}=2.88 ; 95 \% \mathrm{CI}: 1.27-8.31 ; P=$ 0.02) more likely to have uncontrolled BP than those with a diagnosis of $<5$ years. Patients with a monthly BP measurement were $35 \%$ less likely to have uncontrolled $\mathrm{BP}$ than those with every three months BP measurement (AOR 0.65; 95\% CI: 0. 63-0.98; $P=0.04$ ) and nonadherent patients were two times more likely to have uncontrolled BP than adherents (AOR 2.05; 95\% CI: 2.61-9.33; $P=0.01)$. Patients with uncontrolled blood sugar (poor glycemic control) were almost two times $(\mathrm{AOR}=1.65 ; 95 \% \mathrm{CI}: 2.14-3.32 ; \mathrm{P}=0.04)$ more likely to have uncontrolled BP than with controlled blood sugar (Table 4).

\section{Discussion}

Hypertension in patients with diabetes is a wellrecognized cardiovascular risk factor [18]. Recently the 8th Report of the Joint National Committee on prevention, detection, evaluation and treatment of high blood pressure (JNC 8) concluded that BP measurement in diabetic patients should be $140 / 90 \mathrm{mmHg}$ or less [4]. Hypertension is twice as common in persons with diabetes as it is in others. Hypertension is known to contribute to diabetic micro-and macro-vascular complications [19]. To reduce the risk, hypertension must be diagnosed accurately and promptly, and the patient must receive adequate treatment. However, new guidelines have been published to stress on the importance of aggressive blood pressure control in diabetic [2]. This study attempted to evaluate the blood pressure control among diabetic patients in Jimma University medical center.

The result of the study showed that from a total of 131hypertensive diabetics only $43.51 \%$ of the patients met the currently recommended BP for diabetes of $<140 / 90$ $\mathrm{mmHg}$ [4]. The level of BP control found in this study is lower than studies from Chilean (59.7\%) [20], Greece (55.6\%) [19], USA (49.8\%) [21] and South Africa (57\%) [22-24]. It was also lower as compared study done by Greenberg et al. [14] and Berlowitz et al. [25]. But, it comparable with based studies from Adama (43.6\%) [26] and Nigeria (42\%) [27], respectively. This difference in the level of BP control might be due to a diabetes comorbidity 


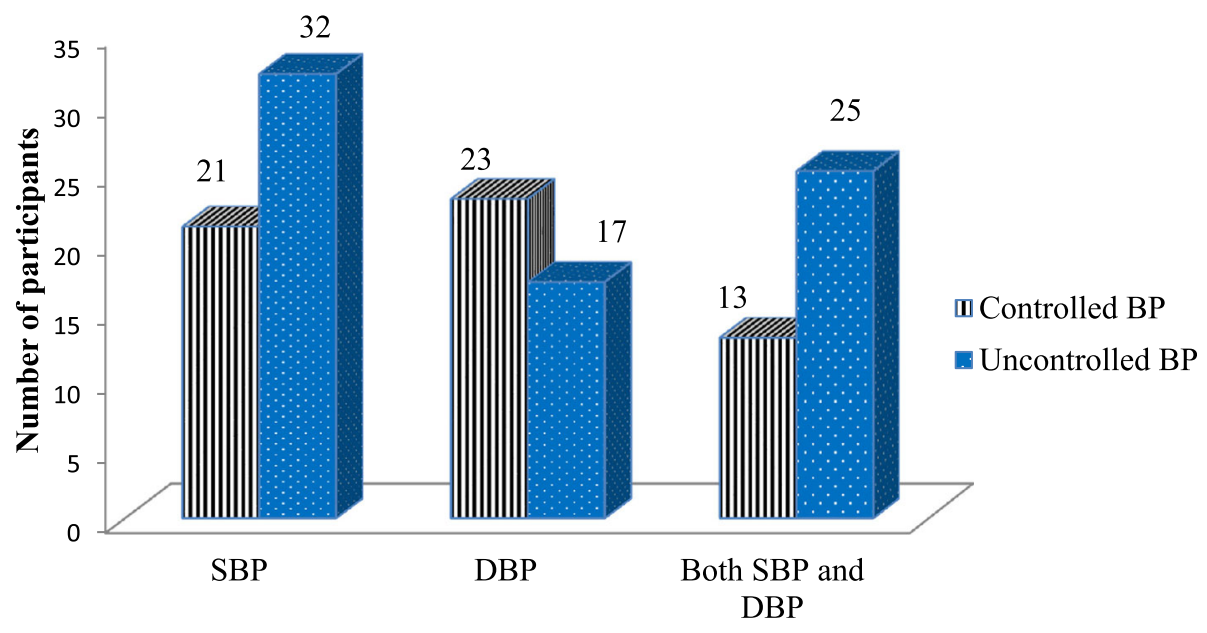

Blood pressure

Fig. 1 Blood pressure control among study participants at JUMC, 2017

of our study population, which may indicate the need of more effort to control BP in diabetics.

This study revealed that 33 (25.20\%) and 36 (27.48\%) of the study participants had a controlled SBP and DBP respectively, which is lower than a report from Saudi Arabia (40.4\% and 51.6\%) [28] and USA (55.7\% and 77.1\%) [29].This difference in the level of control of SBP and DBP might be due to age related increase in SBP as more than half of study participants were older than 50 years of age.

As from this report age was significantly associated with uncontrolled BP in that patients aged greater 50 years were two times more likely to have uncontrolled BP than those younger than 50 years $(\mathrm{AOR}=$ 2.06, 95\% CI: $2.65,7.79, P=0.002)$. It is similar to study done by in USA [29] and Kenya [30]. As well similar to report from Brazil [31], this study showed older age as contributing factor for uncontrolled BP. In fact, an interaction between biological and behavioral factors could be used to explain our results. Regarding biological factors, a possible explanation would be the natural processes related to ageing, such as autonomous imbalance and vessels stiffening. In relation to behavioral factors, previous studies showed that older people have decreased physical activity practice [32].

Educational status was also found to be associated with $\mathrm{BP}$ control in which patients with tertiary education were $38 \%(\mathrm{AOR}=0.26,95 \% \mathrm{CI}: 0.13,0.54, P=0.03$ ) less likely to have uncontrolled BP when compared to those with no formal education. This result is consistent with a result obtained from Chilean $\mathrm{HC}$ study which showed low education level to have a negative association with BP control [20]. This may be is a result of increased awareness regarding the treatment of hypertension, adherence to life style modifications to decrease BP or adherence to antihypertensive drug treatment. The result of the study showed evidence of association of frequent BP measurement with good odds of BP control in which patients with a monthly BP measurement were $35 \%$ less likely to have uncontrolled BP than those with a monthly BP measurement (AOR 0.65, 95\% CI: 0. 63, 0. $98, P=0.04)$ ). This may be is a result of a health seeking behavior, frequent adjustment in life style related factors and a tendency to adhere to antihypertensive medication among those who frequently measure their BP.

Adherence to therapies is a primary determinant of treatment success. Poor adherence attenuates optimum clinical benefits and therefore reduces the overall effectiveness of treatment outcome this study showed that non adherent patients were two times more likely to have uncontrolled BP than adherents (AOR 2.05, 95\% CI: 2.61, 9.33, $P=0.01)$. This result is consistent with the result obtained from studies from South Africa [24], Zimbabwe [33], USA [34] and Nigeria [35].

In light of this result, patients should be counseled and encouraged to adhere to antihypertensive medications, as adherence to antihypertensive medications is a key to achieving an optimal BP, specially, in patient needing intensive BP control, such as comorbid diabetics. Those patients with positive behavioral measures (i.e. smoking, alcohol intake and chat chewing) had higher odds of uncontrolled BP, which is consistent with study done in Saudi Arabia (8.3\%) [28], Oman (8\%) [36] and Zimbabwe (16.1\%) [33]. This could be secondary to the oxidative stress they impose on the cell as well as their effect on adherence [37]. Thus, cessation of cigarette smoking and decreasing/stopping alcohol intake is recommended to achieve an optimal BP among patients with hypertension, specifically comorbid with diabetes. Because, this populations have additional cardiovascular risk equivalent. 
Table 4 Determinants of uncontrolled blood pressure among study participants at JUMC, 2017

\begin{tabular}{|c|c|c|c|c|c|}
\hline \multirow[t]{2}{*}{ Variable } & & \multicolumn{2}{|c|}{ Blood Pressure } & \multirow[t]{2}{*}{ COR $(95 \% \mathrm{Cl})$} & \multirow[t]{2}{*}{ AOR (95\%Cl) } \\
\hline & & Controlled & Uncontrolled & & \\
\hline \multirow[t]{2}{*}{ Age category } & $<50$ years & 20 & 44 & 1.00 & 1.00 \\
\hline & $\geq 50$ years & 37 & 30 & $2.55(1.72,4.75)^{*}$ & $2.06(2.65,7.79)^{*}$ \\
\hline \multirow[t]{2}{*}{ Gender } & Male & 33 & 34 & 1.00 & 1.00 \\
\hline & Female & 24 & 40 & $1.63(0.98,2.90)^{*}$ & $1.42(1.19,2.14)^{*}$ \\
\hline \multirow[t]{4}{*}{ Marital status } & Married & 45 & 64 & 1.00 & 1.00 \\
\hline & Single & 7 & 4 & $2.721(10.59,13.36)$ & $3.42(11.22,14.12)$ \\
\hline & Divorced & 2 & 2 & $0.55(0.14,5.53)$ & $0.49(0.54,1.59)$ \\
\hline & Widowed & 3 & 4 & $1.46(0.22,0.78)^{*}$ & $1.76(0.46,1.27)$ \\
\hline \multirow[t]{4}{*}{ Education level } & No formal education & 7 & 28 & 1.00 & 1.00 \\
\hline & Primary & 12 & 21 & $2.22(1.80,2.84)$ & $0.18(0.15,1.13)$ \\
\hline & Secondary & 15 & 12 & 1. $15(0.98,2.35)$ & $0.07(0.37,1.53)$ \\
\hline & Tertiary and above & 23 & 13 & $0.27(0.34,1.12)^{*}$ & $0.62(0.31,0.45)^{*}$ \\
\hline \multirow[t]{2}{*}{ Residence } & Rural & 18 & 22 & 1.00 & 1.00 \\
\hline & Urban & 39 & 52 & $0.28(1.34,11.75)$ & $2.11(2.47,9.16)$ \\
\hline \multirow[t]{5}{*}{ Monthly income (ETB) } & No regular income & 15 & 26 & $2.17(4.42,6.15)$ & $1.23(0.23,4.74)$ \\
\hline & $<1000$ & 6 & 15 & $1.06(1.24,3.15)$ & $1.09(2.12,6.11)$ \\
\hline & $1000-2000$ & 9 & 10 & $0.69(1.79,3.35)$ & $0.453(0.32,7.42)$ \\
\hline & $2000-3000$ & 7 & 11 & $0.66(0.64,5.59)$ & $0.23(2.32,9.47)$ \\
\hline & $\geq 3000$ & 20 & 12 & 1.00 & 1.00 \\
\hline \multirow[t]{4}{*}{ Occupation } & Gov't employee & 21 & 9 & 1.00 & 1.00 \\
\hline & Non-Gov't employee & 13 & 6 & $0.28(0.34,1.75)$ & $1.10(0.74,2.61)$ \\
\hline & Self employed & 9 & 29 & $0.67(0.27,1.66)$ & $0.68(0.25,1.87)$ \\
\hline & Unemployed & 14 & 30 & $1.06(0.60,1.85)$ & $1.05(0.57,1.94)$ \\
\hline \multirow[t]{2}{*}{ Smoking } & No & 52 & 58 & 1.00 & 1.00 \\
\hline & Yes & 5 & 16 & $1.31(0.75,2.28)^{*}$ & $1.14(0.62,2.10)$ \\
\hline \multirow[t]{2}{*}{ Alcohol intake } & No & 53 & 55 & 1.00 & 1.00 \\
\hline & Yes & 4 & 19 & $1.66(0.46,5.95)^{*}$ & $1.23(0.32,4.74)$ \\
\hline \multirow[t]{2}{*}{ Chat chewer } & No & 42 & 53 & 1.00 & 1.00 \\
\hline & Yes & 15 & 21 & $1.05(0.67,1.66)$ & $1.12(0.68,1.84)$ \\
\hline \multirow[t]{2}{*}{ Adherence } & Adherent & 49 & 48 & 1.00 & 1.00 \\
\hline & Non-adherent & 8 & 26 & 2. $37(2.71,8.65)^{*}$ & $2.05(2.61,9.33)^{*}$ \\
\hline \multirow[t]{3}{*}{ Frequency of follow up } & Monthly & 40 & 31 & $0.35(0.53,0.97)^{*}$ & $0.65(0.63,0.98)^{*}$ \\
\hline & Every 2 months & 10 & 31 & $1.31(0.75,2.28)$ & $1.42(2.26,3.01)$ \\
\hline & Every 3 months & 7 & 12 & 1.00 & 1.00 \\
\hline \multirow[t]{3}{*}{ Duration with Hypertension } & $\leq 1$ year & 13 & 12 & 1.00 & 1.00 \\
\hline & $2-5$ years & 20 & 25 & $0.69(1.36,11.44)$ & $1.11(2.62,6.63)$ \\
\hline & $\geq 5$ years & 24 & 37 & 1. $75(1.59,5.85)^{*}$ & $2.88(1.27,8.31)^{*}$ \\
\hline \multirow[t]{2}{*}{ Blood Sugar } & Controlled & 51 & 35 & 1.00 & 1.00 \\
\hline & Uncontrolled & 6 & 39 & $2.33(2.11,7.15)^{*}$ & 1. $65(2.14,3.32)^{*}$ \\
\hline \multirow[t]{2}{*}{ Comorbidity } & No & 40 & 48 & 1.00 & 1.00 \\
\hline & Yes & 17 & 26 & $1.04(0.44,3.31)^{*}$ & $1.12(1.22,4.45)$ \\
\hline \multirow[t]{3}{*}{ Anti-HTN regimen } & Monotherapy & 13 & 18 & 1.00 & 1.00 \\
\hline & Dual Therapy & 40 & 49 & $048(0.13,1.08)$ & $0.44(1.10,2.11)$ \\
\hline & Triple therapy & 4 & 7 & $1.35(1.79,4.78)$ & $1.68(1.19,3.43)$ \\
\hline
\end{tabular}


This study also reveals that, not only comorbidity with diabetes, but also poor glycemic control is an independent predictor for uncontrolled BP. Patients with poor glycemic control had almost two times $(\mathrm{AOR}=1.65$, $95 \%$ CI: 2. 14 , 3. 32, $P=0.04$ ) more likely to develop uncontrolled BP. This study is consistent with study done in Brazil [31], by Greenberg et al. [14], Berlowitz et al. [25], Adler et al. [38] and Jansson et al. [17]. This could be explained by the pathophysiologic process related specifically to the presence of diabetes may involve excess circulating insulin. Excess circulating insulin, arising from insulin resistance in diabetes, may increase blood pressure by stimulating the sympathetic nervous system, acting as a growth factor, and/or increasing sodium reabsorption in the kidneys [39]. Simply, the release of insulin following a meal stimulates vasodilation (the widening of blood vessels) in skeletal muscle while also activating the sympathetic nervous causing vasoconstriction [40].

\section{Conclusions}

Blood pressure control to target goal was suboptimal and achieved only in almost two fifth of pharmacologically treated hypertensive diabetic patients attending ambulatory clinic of Jimma University Medical Center. Diabetic patients who were older, female, live long duration with hypertension were more likely to have uncontrolled BP. These patients can be clearly identified and therefore preventive measures should concentrate on this group of patients. Older age, female gender, duration of hypertension, non-adherence and uncontrolled blood sugar are independent predictors for uncontrolled blood pressure among hypertensive diabetic patients. Monthly follow up and higher education are protective for blood pressure control.

\section{Acknowledgments}

We would like to express our heartfelt gratitude to the Jimma University, Institute of Health sciences, for giving us the chance to conduct this research. Our acknowledgment extends to all study participants for their time and willingness to respond and to data collectors and the supervisor for their friendly work.

\section{Funding}

This study was sponsored by Jimma University, Ethiopia.

\section{Availability of data and materials}

The data sets generated during and/or analyzed during the current study are available from the corresponding authors on reasonable request.

\section{Authors' contributions}

The analysis was conceptualized by SM, TM, LC, and DA. Data collection was managed by SM, TM and data analysis was conducted by SM \& TM with support from LC and DA. TM drafted the manuscript. All authors (SM, TM, LC, and DA) participated in editing, feedback and revisions. All authors read and approved the final manuscript.

\section{Ethics approval and consent to participate}

Ethical clearance \& approval was obtained from institution review board (IRB) of Jimma University. Before the start of the survey, informed consent was requested and received from the patient.

\section{Consent for publication}

Not applicable.

\section{Competing interests}

The authors have no competing interests to declare. The funder had no role in the study design, data collection and analysis, decision to publish, or preparation of the manuscript.

\section{Publisher's Note}

Springer Nature remains neutral with regard to jurisdictional claims in published maps and institutional affiliations.

\section{Author details}

${ }^{1}$ Department of Clinical Pharmacy, School of Pharmacy, Institute of Health, Jimma University, P.O.Box:378, Jimma, Oromia, Ethiopia. ²Department of Pharmaceutics, School of Pharmacy, Institute of Health, Jimma University, P.O.Box:378, Jimma, Oromia, Ethiopia.

Received: 15 September 2017 Accepted: 30 November 2017 Published online: 27 December 2017

\section{References}

1. Organization WH. A global brief on hypertension: silent killer, global public health crisis: world health day 2013. 2013.

2. Chobanian AV, Bakris GL, Black HR, Cushman WC, Green LA, Izzo JL, et al. Seventh report of the joint national committee on prevention, detection, evaluation, and treatment of high blood pressure. Hypertension. 2003;42(6):1206-52.

3. Longo DL, Fauci AS, Kasper DL, Hauser SL, Jameson JL, Loscalzo J. Harrison's Principles of Internal Medicine 18E Vol 2 EB. McGraw Hill Professional. 2012. p. 1611-1624

4. James PA, Oparil S, Carter BL, Cushman WC, Dennison-Himmelfarb C, Handler J, et al. 2014 evidence-based guideline for the management of high blood pressure in adults: report from the panel members appointed to the eighth joint National Committee (JNC 8). JAMA. 2014;311(5):507-20.

5. $\quad$ Organization WH. Noncommunicable diseases country profiles 2014. 2014.

6. Kuller LH. Epidemic hypertension in sub-Saharan Africa. Hypertension. 2007; 50(6):1004-5.

7. Kearney PM, Whelton M, Reynolds K, Muntner P, Whelton PK, He J. Global burden of hypertension: analysis of worldwide data. Lancet. 2005;365(9455):217-23.

8. Addo J, Smeeth L, Leon DA. Hypertension in sub-Saharan Africa. Hypertension. 2007:50(6):1012-8.

9. Awoke A, Awoke T, Alemu S, Megabiaw B. Prevalence and associated factors of hypertension among adults in Gondar, Northwest Ethiopia: a community based cross-sectional study. BMC Cardiovasc Disord. 2012;12(1):113.

10. Tesfaye F, Byass P, Wall S. Population based prevalence of high blood pressure among adults in Addis Ababa: uncovering a silent epidemic. BMC Cardiovasc Disord. 2009;9(1):39.

11. Molla M. Systematic reviews of prevalence and associated factors of hypertension in Ethiopia: finding the evidence. Sci J Public Health. 2015;3(4):514-9.

12. Kibret KT, Mesfin YM. Prevalence of hypertension in Ethiopia: a systematic meta-analysis. Public Health Rev. 2015;36(1):14.

13. Mancia G, Fagard R, Narkiewicz K, Redon J, Zanchetti A, Böhm M, et al. 2013 ESH/ESC guidelines for the Management of Arterial Hypertension: the task force for the management of arterial hypertension of the European Society of Hypertension (ESH) and of the European Society of Cardiology (ESC). Blood Press. 2013;22(4):193-278.

14. Greenberg JD, Tiwari A, Rajan M, Miller D, Natarajan S, Pogach L. Determinants of sustained uncontrolled blood pressure in a national cohort of persons with diabetes. Am J Hypertens. 2006;19(2):161-9.

15. Morisky DE, Ang A, Krousel-Wood M, Ward HJ. Predictive validity of a medication adherence measure in an outpatient setting. The. J Clin Hypertens. 2008;10(5):348-54.

16. Haskell WL, Lee I-M, Pate RR, Powell KE, Blair SN, Franklin BA, et al. Physical activity and public health: updated recommendation for adults from the 
American College of Sports Medicine and the American Heart Association. Circulation. 2007;116(9):1081.

17. Jansson S, Svärdsudd K, Andersson D. Effects of fasting blood glucose levels and blood pressure and treatment of diabetes and hypertension on the incidence of cardiovascular disease: a study of 740 patients with incident type 2 diabetes with up to 30 years' follow-up. Diabet Med. 2014;31(9):1055-63.

18. Turner R, Millns H, Neil H, Stratton I, Manley S, Matthews D, et al. Risk factors for coronary artery disease in non-insulin dependent diabetes mellitus: United Kingdom prospective diabetes study (UKPDS: 23). BMJ. 1998; 316(7134):823-8.

19. Skliros E, Vasibossis A, Loumakis P, Sotiropoulos A, Giannakaki G, Razis N. Evaluation of hypertension control in Greek primary care units. The VANK study. J Hum Hypertens. 2003;17(4):297.

20. Sandoval D, Bravo M, Koch E, Gatica S, Ahlers I, Henríquez O, et al. Overcoming barriers in the management of hypertension: the experience of the cardiovascular health program in Chilean primary health care centers. Int J Hypertens. 2012;2012:405892.

21. Shelley D, Tseng T-Y, Andrews H, Ravenell J, Wu D, Ferrari P, et al. Predictors of blood pressure control among hypertensives in community health centers. Am J Hypertens. 2011:24(12):1318-23.

22. Adeniyi OV, Yogeswaran P, Longo-Mbenza B, Ter Goon D. Uncontrolled hypertension and its determinants in patients with concomitant type 2 diabetes mellitus (T2DM) in rural South Africa. PLoS One. 2016;11(3): e0150033.

23. Choukem SP, Kengne AP, Dehayem YM, Simo NL, Mbanya JC. Hypertension in people with diabetes in sub-Saharan Africa: revealing the hidden face of the iceberg. Diabetes Res Clin Pract. 2007;77(2):293-9.

24. Onwukwe SC, Omole OB. Drug therapy, lifestyle modification and blood pressure control in a primary care facility, south of Johannesburg, South Africa: an audit of hypertension management. South African. Fam Pract. 2012:54(2):156-61.

25. Berlowitz DR, Ash AS, Hickey EC, Glickman M, Friedman R, Kader B. Hypertension management in patients with diabetes. Diabetes Care. 2003; 26(2):355-9.

26. Hussein M, Lenjisa J, Woldu M, Tegegne G, Umeta G. Assessment of drug related problems among hypertensive patients on follow up in Adama hospital medical college, East Ethiopia. Clinic Pharmacol Biopharmaceut. 2014;3(122):2

27. Adebolu FA, Naidoo M. Blood pressure control amongst patients living with hypertension presenting to an urban district hospital outpatient clinic in Kwazulu-Natal. Afr J Prim Health Care Fam Med. 2014:6(1):1-6.

28. Al-Tuwiji AA, Al-Rukban MO. Hypertension control and co-morbidities in primary health care centers in Riyadh. Ann Saudi Med. 2006;26(4):266.

29. Ornstein SM, Nietert PJ, Dickerson LM. Hypertension management and control in primary care: a study of 20 practices in 14 states. Pharmacotherapy. 2004;24(4):500-7.

30. Mutua EM, Gitonga MM, Mbuthia B, Muiruri N, Cheptum JJ, Maingi T. Level of blood pressure control among hypertensive patients on follow-up in a regional referral hospital in Central Kenya. Pan Afr Med J. 2014;18:278.

31. Codogno JS, Fernandes RA, Freitas Jr IF, Monteiro HL. Determinants of blood pressure in type 2 diabetic subjects with high occurrence of inadequate glycemic control. Medicina (Brazil). 2012;45(1):49-57.

32. Wichi RB, De Angelis K, Jones L, Irigoyen MC. A brief review of chronic exercise intervention to prevent autonomic nervous system changes during the aging process. Clinics. 2009;64(3):253-8.

33. Goverwa TP, Masuka N, Tshimanga M, Gombe NT, Takundwa L, Bangure D, et al. Uncontrolled hypertension among hypertensive patients on treatment in Lupane District, Zimbabwe, 2012. BMC Res Notes. 2014;7(1):703.

34. Elperin DT, Pelter MA, Deamer RL, Burchette RJ. A large cohort study evaluating risk factors associated with uncontrolled hypertension. J Clin Hypertens. 2014;16(2):149-54.

35. Noh GU, Ofoedu JN, Njoku PU, Godswill-Uko EU, Amadi AN. Medication adherence and blood pressure control amongst adults with primary hypertension attending a tertiary hospital primary care clinic in eastern Nigeria. Afr J Prim Health Care Fam Med. 2013;5(1):1-6.

36. Al-Saadi R, Al-Shukaili S, Al-Mahrazi S, Al-Busaidi Z. Prevalence of uncontrolled hypertension in primary care settings in al seeb wilayat, oman. Sultan Qaboos Univ Med J. 2011:11(3):349.
37. Davis TM, Millns H, Stratton IM, Holman RR, Turner RC. Risk factors for stroke in type 2 diabetes mellitus: United Kingdom prospective diabetes study (UKPDS) 29. Arch Intern Med. 1999;159(10):1097-103.

38. Adler Al, Stratton IM, Neil HAW, Yudkin JS, Matthews DR, Cull CA, et al. Association of systolic blood pressure with macrovascular and microvascular complications of type 2 diabetes (UKPDS 36): prospective observational study. BMJ. 2000;321(7258):412-9.

39. Singh M, Mensah GA, Bakris G. Pathogenesis and clinical physiology of hypertension. Cardiol Clin. 2010;28(4):545-59.

40. Muniyappa R, Montagnani M, Koh KK, Quon MJ. Cardiovascular actions of insulin. Endocr Rev. 2007;28(5):463-91.

\section{Submit your next manuscript to BioMed Central and we will help you at every step:}

- We accept pre-submission inquiries

- Our selector tool helps you to find the most relevant journal

- We provide round the clock customer support

- Convenient online submission

- Thorough peer review

- Inclusion in PubMed and all major indexing services

- Maximum visibility for your research

Submit your manuscript at www.biomedcentral.com/submit
C Biomed Central 